\title{
Os primeiros anos do curso de graduação de Psicologia da FADAFI/FUCMT (1974-1980)
}

\author{
The first years of the undergraduate program of Psychology at the FADAFI/FUCMT \\ (1974-1980)
Los primeros años del curso de pregrado de Psicología de la FADAFI/FUCMT (1974-1980)

\author{
Graciela Ferreira Delmondes ${ }^{1}$ \\ Rodrigo Lopes Miranda²
}

Recebido em 29/05/2019; revisado e aprovado em 19/09/2019; aceito em 31/10/2019. DOI: http://dx.doi.org/10.20435/inter.v21i1.2592

\begin{abstract}
Resumo: Contemporaneamente, a História da Psicologia latino-americana tem se debruçado sobre os mecanismos de institucionalização da Psicologia e, nessa seara, a história dos cursos de graduação tem sido um objeto frequente. No caso brasileiro, entretanto, essa produção focaliza instituições e espaços específicos localizados, via de regra, nas regiões Sul e Sudeste do país. Assim, tornam-se prementes as investigações em História Regional, i.e., aquelas que consideram o desenvolvimento da Psicologia em outras localidades. Diante disso, esta investigação descreve e analisa demandas de criação do curso de graduação em Psicologia, instalado na Faculdade Dom Aquino de Filosofia, Ciências e Letras/Faculdades Unidades Católicas de Mato Grosso (FADAFI/FUCMT), em 1975. Além disso, são analisados aspectos de seu currículo de funcionamento. Este foi o segundo curso de Psicologia do estado de Mato Grosso e o único de Campo Grande, até 1999. Para atingir o objetivo proposto, esta pesquisa, circunscrita ao campo da História da Psicologia, possui como recorte temporal o período de formação da primeira turma (1974-1980) e utiliza fontes primárias textuais e orais. A interpretação das fontes, em face dos elementos contextuais de Mato Grosso à época, sugere a Missão Salesiana de Mato Grosso (MSMT) como vetor importante do desenvolvimento do Ensino Superior no estado. Além disso, nota-se uma estreita relação entre a conformação do curso de graduação investigado e o cenário de modernização alardeado no segundo e terceiro quartis do século XX, no país. Por fim, vê-se que o curso foi estabelecido de forma idiossincrática, atendendo a uma maioria de alunas, rememoradas como maduras e politizadas. Assim, apesar das limitações metodológicas do estudo, seus resultados auxiliam em uma compreensão ampliada da história da Psicologia no Brasil. Eles possibilitam, ainda, uma melhor compreensão das relações entre Igreja e Estado, no que tange ao estabelecimento dos cursos de Psicologia no país.
\end{abstract}

Palavras-chave: história da Psicologia; história regional e local; salesianos; FADAFI/FUCMT.

Abstract: Recently, History of Psychology in Latin American has been focusing on the mechanisms of institutionalization of Psychology and, in this scenario, the history of undergraduate programs has been a recurrent object. Considering Brazil, such research focuses on specific institutions located, mainly, in the South and Southeast regions of the country. Thus, research in Regional History has become urgent, i.e., that considers the development of Psychology in other locations of the country. This study describes and analyzes social demands for the establishment of the undergraduate program of Psychology at the Faculdade Dom Aquino de Filosofia, Ciências e Letras/Faculdades Unidades Católicas de Mato Grosso (FADAFI/FUCMT), in 1975. In addition to this, it reflects upon its curriculum. This was the second undergraduate program of Psychology from the state of Mato Grosso and the only one in Campo Grande until 1999. To achieve its main goal, this study highlights the timeframe of training of the first class (1974-1980) and it uses primary textual and oral sources. The interpretation of these sources connected to the contextual aspects of Mato Grosso at the time, suggests the Missão Salesiana de Mato Grosso (MSMT) as an important vector of the development of Higher Education in the state. In addition to this, it was observed a close relationship between the creation of the undergraduate course investigated and the scenario of modernization promoted in the second and third quartiles of the $20^{\text {th }}$ century, in the country. Finally, it is seen that this program was established idiosyncratically, serving a majority of women, remembered as mature and politicized. Thus, despite the methodological constraints of the study, its results help in an extended understanding of the history of Psychology in Brazil.

\footnotetext{
${ }^{1}$ Universidade Anhanguera-Uniderp, Campo Grande, Mato Grosso do Sul, Brasil.

${ }^{2}$ Universidade Católica Dom Bosco (UCDB), Campo Grande, Mato Grosso do Sul, Brasil.
} 
They also make possible a better understanding of the relationship between Church and State in relation to the establishment of Psychology undergraduate programs in the country.

Keywords: history of Psychology; local history; salesians; FADAFI/FUCMT.

Resumen: Contemporáneamente, la Historia de la Psicología latinoamericana se ha centrado en los mecanismos de institucionalización de la Psicología y, principalmente, en la historia de los cursos de pre graduación ha sido un objeto frecuente. En el caso brasileño, sin embargo, esa producción focaliza instituciones y espacios específicos localizados, por regla general, en las regiones Sur y Sudeste del país. Así, se vuelven apremiantes las investigaciones en Historia Regional, i.e., aquellas que consideran el desarrollo de la Psicología en otras localidades. En este sentido, esta investigación describe y analiza las demandas sociales para el establecimiento del curso de pre graduación en Psicología, instalado en la Faculdade Dom Aquino de Filosofía, Ciencias e Letras/Faculdades Unidades Católicas de Mato Grosso (FADAFI/FUCMT), en 1975. Además de esto, refleja sobre su currículum. Ese fue el segundo curso de la Psicología del estado de Mato Grosso y el único de Campo Grande, hasta 1999. Para alcanzar el objetivo propuesto, esta investigación, circunscrita al campo de la Historia de la Psicología, posee como recorte temporal el período de formación de la primera clase (19741980) y utiliza fuentes primarias textuales y orales. La interpretación de las fuentes, en vista de los elementos contextuales de Mato Grosso en la época, sugiere la Missão Salesiana de Mato Grosso (MSMT) como vector importante del desarrollo de la enseñanza superior en el estado. Además, se nota una estrecha relación entre la conformación del curso de pre graduación investigado y el escenario de modernización alardeado en el segundo y tercer cuartiles del siglo XX, en el país. Por último, se ve que el curso fue establecido de forma idiosincrática, atendiendo a una mayoría de alumnas, rememoradas como maduras y politizadas. Así, a pesar de las limitaciones metodológicas del estudio, sus resultados auxilian en una comprensión ampliada de la historia de la Psicología en Brasil. Ellos posibilitan, aún, una mejor comprensión de las relaciones entre Iglesia y Estado, en lo que se refiere al establecimiento de los cursos de Psicología en el país.

Palabras clave: historia de la Psicologia; historia local; salesianos; FADAFI/FUCMT.

\section{INTRODUÇÃO}

De forma geral, nos últimos anos, a História da Psicologia latino-americana tem se debruçado sobre os mecanismos de institucionalização da Psicologia, em diferentes países (cf. PIÑEDA; JACÓ-VILELA, 2014; SALVATIERRA, 2015). Nesta seara, analisam-se os processos de criação de associações da área, de circulação de periódicos e, especialmente, o surgimento e o funcionamento inicial dos cursos de graduação. No caso específico do Brasil, essas histórias nos apontam uma relação do surgimento dos primeiros cursos de graduação em Psicologia, com o fortalecimento de um ideário "modernizador", gestado na República Velha (1889-1930), mas intensificado entre as décadas de 1930 e 1960, como nos governos de Getúlio Vargas (1930-1945) e Juscelino Kubitschek (1956-1961). Todavia grande parte delas focaliza a criação e o funcionamento dos cursos de graduação de Psicologia em instituições no Sul e Sudeste brasileiro (e.g., FERRAZ, 2014; MARGOTTO; SOUZA, 2017).

Dessa forma, tem se tornado tarefa premente a historicização dos processos de institucionalização da Psicologia, em diferentes regiões do país. Para tanto, faz-se mister considerar que as diferenças regionais brasileiras se manifestam tanto em termos socioeconômicos quanto no desenvolvimento científico e tecnológico, dada a tradição em centros de pesquisa e os investimentos financeiros (SIDONE; HADDAD; MENA-CHALCO, 2016). Especificamente, as pesquisas sobre a história da Psicologia, em tais regiões, têm mostrado a necessidade da consideração de outras temporalidades para a análise dos processos de institucionalização e, ainda, o enfoque em características locais que produziram a demanda para a instituição daqueles cursos (e.g., CARA et al., 2018; RODRIGUES, 2013). Consequentemente, produzir histórias regionais pressupõe que determinadas especialidades, perante as especificidades locais, produziram mecanismos singulares de apropriação e institucionalização da Psicologia. 
Diante desse cenário, este artigo objetiva historicizar os momentos iniciais do curso de graduação em Psicologia, instalado nas Faculdades Unidas Católicas de Mato Grosso (FUCMT) ${ }^{3}$, em 1975. Mais particularmente, são descritos e analisados aspectos das demandas e necessidades de criação do referido curso, bem como seu currículo. Metodologicamente, a pesquisa se insere no campo da História Social da Psicologia, portanto, interessada na compreensão de condicionantes socioculturais que ensejam a produção do acontecimento histórico (PORTUGAL; FACCHINETTI; CASTRO, 2018). Para tanto, ela se vale de uma perspectiva da História Regional e Local, i.e., em uma possibilidade de produzir histórias que consideram territórios sociais, científicos e institucionais idiossincráticos (CORSI, 2011). Isso se torna ainda mais premente no Brasil, um país de dimensões continentais.

Para alcançar tal objetivo, foram analisadas fontes primárias textuais e orais. As primeiras consistiam em documentos vinculados à criação e ao funcionamento do curso, tais como cartas, atas de reuniões, ofícios, documentos, pedidos de autorização e funcionamento, grades curriculares, entre outros. As segundas eram compostas por produtos de entrevistas com cinco docentes que atuaram na formação da primeira turma de psicólogos da Faculdade Dom Aquino de Filosofia, Ciências e Letras/Faculdades Unidades Católicas de Mato Grosso (FADAFI/ FUCMT). Vale ressaltar que todos os entrevistados assinaram um Termo de Consentimento Livre e Esclarecido (TCLE), que permitia sua identificação nominal em qualquer publicação advinda do estudo. A pesquisa e todos os seus procedimentos foram aprovados por um Comitê de Ética em Pesquisa, sendo ela registrada pelo CAAE 55239916.5.0000.5162 e Parecer n. 1.532.583. O recorte temporal eleito para análise abrangeu os anos entre 1974 e 1980, compreendendo o período das primeiras reuniões para a criação do curso e a formação da primeira turma, respectivamente.

Assim, para atingir o objetivo proposto, este artigo organiza-se em duas seções. A primeira introduz o cenário local de instalação do curso de graduação em Psicologia da FADAFI/FUCMT, salientando a chegada da Ferroviária Noroeste do Brasil (NOB), no sul do Mato Grosso (MT), bem como as condições idiossincráticas de Campo Grande e as relações desse cenário com a alardeada modernização nacional do segundo e terceiro quartis do século XX. Na segunda, analisam-se os aspectos da criação e funcionamento inicial do curso de Psicologia, na FADAFI/FUCMT, a partir da articulação entre a memória dos docentes e as fontes textuais, enfatizando a sua estrutura, o perfil dos acadêmicos e suas relações com os docentes e as disciplinas. Ao final, estima-se concluir que a criação do curso de graduação de Psicologia historicizado se ancora em dois contextos. Um deles, generalizado, aborda o fortalecimento de discursos e práticas de "modernização" do país, e outro, específico de MT, refere-se ao papel dos salesianos e às influências das controvérsias entre o norte e o sul do estado, à época. Dessa forma, a partir da articulação entre diferentes tipos de fontes de pesquisa, foi possível tatear certos horizontes sociais que auxiliam na compreensão da instalação e do funcionamento inicial do primeiro curso de graduação em Psicologia da cidade de Campo Grande e único até os últimos momentos do século XX.

\footnotetext{
${ }^{3}$ Deste momento em diante, será feita referência ao curso de graduação em Psicologia como vinculado à FADAFI/ FUCMT. A primeira instituição é precursora da segunda e, dessa forma, as fontes primárias pesquisadas ora indicam a criação do curso na FADAFI, ora na FUCMT. Diante do exposto, optou-se pelo uso do binômio FADAFI/FUCMT para referência ao curso de graduação em Psicologia que aqui se historiciza.
} 


\section{ENSINO SUPERIOR E FORMAÇÃO EM PSICOLOGIA: UMA DEMANDA DE MODERNIZAÇÃO DO CENTRO-OESTE}

No final do século XIX, a região Centro-Oeste era pouco habitada, se comparada com as regiões Sul, Sudeste e Nordeste. Uma explicação para essa diferença seria a tardia ocupação da região. Em um cenário ampliado, a economia brasileira destacava-se com o plantio do café, cuja concentração estava na região do Vale do Paraíba, entre os estados do Rio de Janeiro (RJ) e de São Paulo (SP), em que a mão de obra escrava negra era, gradativamente, substituída pelo trabalho dos imigrantes, nas lavouras. O estado de São Paulo era responsável pela metade da produção de café no Brasil. Assim, começava a se constituir como um polo urbano e industrial que necessitava de profissionalização e, consequentemente, de educação. Nesse cenário, a divisão com o estado de São Paulo e o período econômico em que ele se encontrava são fatores pertinentes para a compreensão do processo e do desenvolvimento da região Centro-Oeste e, especificamente, do sul de MT. No processo em questão, destaca-se a construção da NOB, i.e., da expansão ferroviária já existente, com o intuito de facilitar o escoamento da produção de café, além de povoar regiões do Brasil pouco habitadas, como a região Centro-Oeste.

A NOB tinha, em seu projeto, a função de abrir novas áreas para a expansão da agricultura cafeeira. Ligou as cidades de Bauru, no interior de São Paulo, a Corumbá, no sul de MT. A NOB, cuja construção se iniciou em 1905 e foi concluída em 1914, aportava em lugares com pouca ou nenhuma ocupação urbana, possibilitando o surgimento de várias cidades no país. Entre as áreas beneficiadas pela NOB, podemos aludir o desenvolvimento na região sul de MT. Cuiabá, capital do estado, possuía transporte fluvial e, após a inauguração da NOB, passou a ser considerada como um local de difícil acesso, pois o transporte ferroviário se revelava mais rápido e acessível. Ao passo que Cuiabá tornava-se distante, Campo Grande destacava-se como principal cidade do sul do estado, devido ao transporte ferroviário. Nesse contexto, a chegada dos imigrantes determinou o aumento da população vinda para o sul do estado, para a construção da NOB. Após o seu término, esses trabalhadores ali se fixaram. Surgiu, então, uma maior demanda por educação na região. Nesse cenário, a Missão Salesiana de Mato Grosso (MSMT) foi fundamental para o processo do fortalecimento da educação no lugar. A partir da NOB, os salesianos firmados no interior de SP puderam se locomover, com maior rapidez, para as regiões do sul de MT, se comparado aos outros meios de transporte à época.

As atividades da congregação Salesiana, no Brasil, iniciaram-se em 1883. Nesse cenário, em 1894, ocorreu uma das primeiras expedições de salesianos para onde seria o estado de MT. Seu objetivo era catequizar os índios e educar os jovens e, ainda naquele mesmo ano, eles inauguraram, em Cuiabá, o Liceu de Artes e Ofícios São Gonçalo. Nele, eram oferecidos cursos profissionalizantes que capacitavam os jovens, o que permitia que eles se habilitassem profissionalmente, sem precisarem se deslocar para o Sudeste, em busca da educação formal (ROMERO, 2005). Os salesianos chegaram a Corumbá em 1899, período de destaque da cidade entre as que se localizavam no sul do estado, em decorrência de sua localização portuária. Nessa última cidade, fundaram o Colégio Santa Teresa, que atendia à demanda educacional da região sul de MT. Esse investimento educacional também se dava em outras regiões com missões Salesianas, e.g., em SP e no RJ, ocupando-se da educação das camadas populares (CASTRO, 2014). Assim, há indícios de que as obras salesianas favoreceram as famílias e a sociedade, pois as crianças não precisariam mais ser enviadas a internatos em outros estados do país. 
No cenário nacional, no início do século XX, o Ensino Superior estava relegado à formação de elites e direcionado às profissões liberais. A escola superior funcionava em período parcial (conferências). No entanto o contexto de crescimento econômico e a expansão nacional de territorialização promoveram um despertar nacional para o investimento em educação da sociedade. Nesse contexto, durante o governo do presidente Epitácio Pessoa (1919-1922), mudanças significativas na área da educação superior começaram a acontecer, e.g., criou-se, entre outras, a Universidade do Rio de Janeiro. Consolidou-se, no cenário, a participação do setor privado na educação, particularmente no Ensino Superior. Entre os anos de 1933-1960, o setor privado foi responsável por $43 \%$ das matrículas naquele nível de ensino (ROMERO, 2005).

Com a instalação do governo civil-militar, a partir de 1964, esse processo de expansão e fortalecimento do Ensino Superior foi reconfigurado, particularmente a partir da chamada Reforma Universitária, em 1968. Entre as variadas mudanças, destaca-se (i) a centralização das decisões das questões administrativas das universidades à administração federal, (ii) a extinção da cátedra e (iii) o estabelecimento de um currículo básico para todos os cursos (MOTTA, 2014). Paralelamente, a aproximação com setores privados para o Ensino Superior se intensificou. Nessa direção, Sampaio (2000, p. 57) afirma: "No período de 1960-1970, enquanto as matrículas públicas registravam crescimento da ordem de $260 \%$, as do setor privado cresciam mais de $500 \%$ ". Outro fenômeno observado foi o crescimento de novos cursos, no final da década de 1970. Ainda de acordo com este autor, houve a criação de 209 novos cursos, chamados de "carreiras modernas", e.g., Psicologia, Arquitetura, entre outros.

O trabalho dos salesianos, na área educacional, iniciada em Campo Grande em 1929, parecia atender aos interesses da população e do governo, visto que o último não supria a demanda de crianças e jovens que buscavam escolarização. Dessa forma, os salesianos expandiram suas atividades e, em meados de 1950, iniciaram algumas tentativas de implantação de escolas superiores. Sua concretização ocorreu, entretanto, apenas em 1961, com a criação da FADAFI, na cidade de Campo Grande. Em 1965, instalou-se a Faculdade de Direito de Campo Grande (FADIR); em 1970, a Faculdade de Ciências Econômicas, Contábeis e Administrativas (FACECA) e, em 1972, a Faculdade de Serviço Social (FASSO).

A criação das faculdades remete a um cenário ampliado da região, à época. Primeiramente, esse foi um período de transformações no Centro-Oeste, que se iniciaram na década de 1960, quando ocorreu um considerável aumento da população. Essas mudanças levam ao segundo aspecto, vinculado, especificamente, ao Ensino Superior. Há indícios de que os governos estaduais e federal reconheciam, nas Instituições de Ensino Superior (IES), um meio de manter a população residindo no estado. Tal fato fortaleceria a economia da região. A administração de Campo Grande buscava recursos federais para criar uma universidade pública na cidade, mas não há indícios de criação de novas faculdades ou universidades no local até o início da década de 1960 (CASTRO, 2014). A título de exemplo, em 1962 foi criada a Faculdade de Farmácia e Odontologia de Campo Grande, absorvida, a posteriori, pelo Instituto de Ciências Biológicas, onde também se instalou um curso de graduação em Medicina, em 1966. Concomitantemente, institutos e faculdades foram criados em várias cidades do sul do estado, ampliando e reorganizando o Ensino Superior na região, antes mesmo da Reforma Universitária, estabelecida pelo governo militar. Em 1967, foi fundado o Instituto Superior de Pedagogia de Corumbá (ISPC) e instalou-se, em Três Lagoas, o Instituto de Ciências Humanas e Letras. Em 1969, foi criada a Universidade do Estado de Mato Grosso (UEMT), com sede em Campo Grande, pela Lei n. 2.947/1969. Assim, o ocorrido 
em MT parece ser parte do cenário geral do Ensino Superior no Brasil, i.e., certo investimento dos governos estaduais e federal para ampliação e desenvolvimento, mas com forte presença e pioneirismo de instituições privadas.

\section{TECENDO HISTÓRIAS: PRIMEIROS ANOS DO CURSO DE GRADUAÇÃO EM PSICOLOGIA}

\subsection{Instalação e estrutura inicial}

Embora o curso de graduação em Psicologia da FADAFI/FUCMT seja o segundo de MT - o primeiro foi instalado em 1967, em Corumbá, no ISPC -, ele foi o primeiro da cidade, aberto em 1975. Entre os diversos aspectos na criação do curso, chama a atenção a escolha de Campo Grande, e não da capital, Cuiabá, ou de Corumbá, centro importante na dinâmica social do sul do estado. Primeiramente, vale lembrar o desenvolvimento econômico promovido pela NOB, por exemplo, "a arrecadação municipal de Campo Grande chegou ao dobro da arrecadação de Cuiabá no ano de 1963" (BITTAR; SILVA; VELOSO, 2003, p. 149). Em segundo lugar, a NOB facilitou a mobilidade dos salesianos, do interior de São Paulo para o estado. Nessa direção, nota-se que a congregação já possuía faculdades com ensino de Psicologia no interior de SP, como na cidade de Lorena. Portanto a mobilidade facilitada poderia trazer membros do clero, com expertise nessa área do ensino. No cruzamento das possibilidades interpretativas, atente-se para o sinalizado pela MSMT:

Campo Grande, situada no estado do Mato Grosso, por sua situação geográfica, pelo que recebe de rodovias e ferrovia, pelo seu comércio, pelas indústrias, agricultura desenvolvida e escolas superiores, tornou-se a Capital Econômica do Estado. Possui 417 indústrias, 2.617 estabelecimentos comerciais, 22 agências bancárias e 10 hospitais. Quanto ao ensino: Reconhecimento de 1970-Estabelecimentos de 10 Grau-117, Estabelecimento de 20 Grau-22, Estabelecimento de ensino superior-5, Matrículas no 10 Grau-22.077. (BRASIL, 1974, n. p.).

Apesar de os números parecerem superestimados para o cenário regional, à época, eles coadunam com aquele desenvolvimento socioeconômico produzido pela NOB.

Além disso, em outra documentação da Missão, lê-se: "A instalação do curso permite atender à demanda de problemas licenciados para o ensino médio, de matrículas, além de impedir deslocamento de alunos de todo sul de MT para locais fora do Estado" (BRASIL, 1974, p. 5). Assim, o investimento em cursos superiores, em Campo Grande, poderia vincular-se ao cenário de modernização do sul do estado. No caso específico da Psicologia, poderia auxiliar na (i) manutenção da população na região, e (ii) essa população poderia contribuir com o ensino no estado. Vale lembrar que tanto o curso do ISPC quanto o da FADAFI/FUCMT foram criados como Licenciatura Plena, sendo que a formação em Psicologia só ocorreria, na segunda IES, a partir de 1979.

De acordo com os entrevistados desta investigação, houve diversos debates relacionados à instalação e ao funcionamento inicial do curso, entre 1974 e 1980. Sobre o planejamento do curso, Aurenice Rodrigues Pinheiro Pilatti $(2017)^{4}$, coordenadora do Centro de Ciências Humanas da FADAFI/FUCMT à época, relata:

\footnotetext{
${ }^{4}$ Com o intuito de identificar os entrevistados, atores da história ora produzida, adota-se o seguinte procedimento: o nome completo de cada pessoa será apresentado na primeira vez em que forem citados. A partir daí, será feito o uso apenas do sobrenome, como usual nas normatizações acadêmicas.
} 
Eu me recordo que foi, assim, uma notícia muito alvissareira, quando o padre Waldir [Boghossian] chegou e nos disse que estava indo para Brasilia. Foi uma correria de professores. Eu entrei na dança também, como coordenadora lá do Centro de Ciências Humanas, para preparar a documentação que era exigida, na época, pelo MEC, para dar entrada na criação do curso de Psicologia. Então isso criou uma expectativa muito grande aqui em Campo Grande.

Em outra entrevista, com Benedito Juberto Teixeira (2016) - professor de Psicologia Industrial I e II, quando da criação do curso -, notam-se outros aspectos dos momentos iniciais de constituição do curso, bem como a forma como ele foi programado pelos salesianos, professores e demais pessoas envolvidas em seu surgimento. Em suas palavras:

Eu cheguei aqui no estado em 1974, e já nesta ocasião um dirigente da Faculdade FUCMT fez um contato rápido comigo, mas que não evoluiu. Muito poucos psicólogos, acho que quase inexistentes na cidade, então entendi que eles estavam tentando montar um curso.

Assim, a "expectativa muito grande", sinalizada por Pilatti, poderia se referir ao burburinho na busca de professores, sobretudo psicólogos, para a composição do quadro docente. Poderia, também, referir-se aos efeitos locais na sociedade. Nessa direção, a literatura mostra que a criação do curso de Psicologia e os primeiros vestibulares foram pauta frequente dos jornais locais (CARA et al., 2018).

Diferentes entrevistados sinalizaram que Campo Grande, à época, era uma cidade "pequena" e que, nesse cenário, a instalação de cursos de graduação na FADAFI/FUCMT movimentava a cidade (MACÁRIO, 2016; PILATTI, 2017). Nas palavras de Irma Macário (2016), uma das responsáveis pela criação da Clínica do curso de graduação em Psicologia:

Os lugares onde você tinha um número maior de pessoas era ali na FUCMT, no colégio Dom Bosco, pois eles eram espaços que tinham uma representação social grande né. E a Psicologia, né, eram cursos muito importantes até para o próprio desenvolvimento da cidade, né, formação dos professores. A FUCMT teve um papel muito importante para o desenvolvimento da cidade e para o desenvolvimento intelectual, formação profissional dos primeiros profissionais que trabalharam na área, então ele teve uma importância muito grande.

Essa movimentação, inclusive, guardava relação com a composição do corpo docente. De acordo com Luiz Salvador de Miranda Sá Júnior (2016), alguns nomes se destacaram no planejamento do curso, entre eles, o de Padre Scampini: "O Padre Scampini [primeiro diretor-geral da FUCMT] organizou tudo!". Segundo o entrevistado, o eclesiástico foi responsável pelo planejamento e organização do curso de Psicologia e, inclusive, tal referência se coaduna à notícia divulgada pelo jornal Diário da Serra, no dia 24 de janeiro de 1975 (DIÁRIO DA SERRA, 1975a). Entre os demais nomes citados pelos entrevistados desta pesquisa, para o planejamento do curso, destacaram-se: (i) Padre Waldir Boghossian, nome que também aparece em fontes textuais primárias analisadas; (ii) Maria Teodorowick Reis, professora de Psicologia Social I e II, além de Psicologia da Personalidade e (iii) Sonia Grubits, professora de Psicologia Geral e Experimental (DIÁRIO DA SERRA, 1975a).

Nas lembranças de Pilatti (2017):

Eu estava ali, na execução do dia a dia da faculdade, então eu não tive muita participação na elaboração. Sei que a professora Maria [Teodorowick] participou bastante de reuniões, com ele, na parte documental; a Sonia Grubits também participou na parte documental. E 
a própria secretaria da faculdade, quem comandava era o padre Walter Bocchi. Então, os documentos que eram solicitados, o Padre Waldir corria atrás junto com esses profissionais, eu apenas acompanhava por cima, não participei da elaboração do curso. São os documentos que geralmente se pede para a criação de um curso. Primeiro se existe campo para isso, se existe interesse, se existem professores qualificados, isso é muito importante também, não é? Aí as grades curriculares, tudo de acordo com as orientações que vêm prontas do MEC, currículo geral, currículo específico!

Dessa forma, enquanto os professores e membros da Missão se movimentavam para a criação do curso - e.g., estabelecimento de infraestrutura, contratação, projeto curricular -, a sociedade local se mobilizava para investir em tal curso, com matrículas.

Essa infraestrutura para receber o curso foi o Colégio Dom Bosco, instituição de ensino da MSMT, instalada no centro da cidade de Campo Grande. Nas lembranças dos entrevistados, a estrutura física foi considerada adequada e satisfatória, com descrições de salas grandes e arejadas, varandas e janelões. Especificamente, Maria Teodorowick Reis (2016) diz:

As salas de aula são as salas QUE dão para frente da Avenida Mato Grosso, salas enormes, muito boas, arejadas, tinham aqueles corredores... Tinha as salas, depois tinha uma varandona que dava para o interior. Então, no intervalo dava para sair, pra bater papo... ah! Excelente o espaço, salas grandes, arejadas.

Em direção similar, Macário (2016) salienta:

E o primeiro bloco, aquele que entramos, o primeiro bloco à direita, era ali que ficava o curso de Psicologia. Toda a parte teórica ficava lá. A clínica ficava em cima do bloco D, que é o bloco do fundo. Em cima dos banheiros dos alunos do colégio Dom Bosco, vários banheiros e uma gráfica, tinha uma gráfica lá, do colégio Dom Bosco e da FUCMT. No térreo ficava o departamento financeiro e o departamento de RH. Departamento de pessoal, que não era RH ainda, e a gente subia uma escada e a clínica ficava em cima.

Com essa infraestrutura, o curso poderia abrigar as 80 vagas que foram ofertadas em seu lançamento. Inclusive, o prédio alojaria um curso pré-vestibular, para a seleção do curso de Psicologia, com "cerca de 200 candidatos" (DIÁRIO DA SERRA, 1975a). Assim, as fontes textuais e orais sugerem (i) um interesse da sociedade local no referido curso e (ii) um investimento da MSMT na recepção dos alunos e na conformação do curso que, como se verá, possuía algumas características específicas.

\subsection{Perfil discente: mulheres no Ensino Superior mato-grossense}

O curso de graduação em Psicologia da FADAFI/FUCMT teve início em agosto de 1975, após a seleção de 80 candidatos dos 192 inscritos e, entre os aprovados, 62 foram mulheres (DIÁRIO DA SERRA, 1975b; 1975c). Essa característica, inclusive, causou impacto também na mídia local, à época (CARA et al., 2018). No jornal Diário da Serra, de 13 de agosto de 1975, leem-se duas chamadas: "Vestibular de Psicologia: outra conquista das mulheres" e "Vestibular de Psicologia: mulheres conquistam a maioria das vagas". Nessa direção, Reis (2016) diz:

Me lembro do primeiro dia que eu fui dar aula na Psicologia. Eu estava chegando, quando se aproximou de mim uma de minhas alunas [...] "Você não imagina como estou feliz por estar aqui, poder estudar". Mas o que foi [...], o que houve? "Imagina que agora o meu marido soube que a faculdade é católica e que, no curso, a maioria são mulheres, ele me deixou estudar. 
No mesmo sentido, ela continua, a partir do fato de também lecionar para o curso de graduação em Medicina da UEMT, descrevendo uma característica que the chamou a atenção: as mulheres eram minoria na Medicina; já no curso de graduação em Psicologia ocorria o contrário, as mulheres eram maioria. Segundo seu relato, "[...] de repente, ali, eu vi aquelas quase oitenta mulheres com meia dúzia de homens, me chamou atenção". As lembranças da entrevistada sugerem aspectos socioculturais do Brasil, entre as décadas de 1960 e 1970, e sua relação com a "carreira moderna" (SAMPAIO, 2000) de Psicologia. Esse período coincide com diversas transformações sociais para as mulheres, como a assinatura da Lei n. 6.515/77, conhecida como Lei do Divórcio, além de sua inserção cada vez mais ampla e consolidada no mercado de trabalho e as consequentes mudanças nos papéis familiares. Tais mudanças impactaram, sobremaneira, as mulheres brancas da classe média, vinculadas, primordialmente, ao ambiente citadino em promoção à época.

Na maioria das entrevistas, a primeira turma de alunos do curso de graduação em Psicologia foi descrita como uma turma excelente, com alunos maduros, interessados, dedicados e que estavam ansiosos por cursar Psicologia. Nas décadas de 1960 e 1970, pessoas mais velhas que possuíam empregos e não cursaram o Ensino Superior acreditavam ter melhores oportunidades com um diploma, além de melhorarem seu status nas comunidades locais (SAMPAIO, 2000). Nessa mesma direção, Sá Júnior (2016) observa que a maioria das pessoas era casada e com família formada, muitas já trabalhavam na cidade, alguns atuando na área da Educação. As lembranças de Macário (2016) reforçam as ideias contidas nas lembranças de Sá Júnior, i.e., o fato de a primeira turma ser composta por pessoas mais velhas, constituindo um elemento positivo para a qualidade do curso de graduação em Psicologia da FADAFI/FUCMT. Em suas palavras:

Nas primeiras turmas os alunos não eram jovenzinhos como a gente tem hoje! Não eram adolescentes, né! Eram pessoas adultas, alguns que já eram profissionais, que estavam em um segundo curso! Um perfil mais adulto e mais amadurecido! E isso dava um "up" para o curso, né, isso era importante!

Vale a pena lembrar que a única cidade de MT que oferecia o curso de graduação em Psicologia era Corumbá. Para alunos que trabalhavam e tinham família em Campo Grande, mudar para outra cidade, em busca da formação em Psicologia, parecia não ser uma opção. Tal fato poderia explicar a presença de pessoas mais maduras na primeira turma do curso de graduação em Psicologia da FADAFI/FUCMT. Além disso, se a maioria das alunas eram mulheres que necessitavam da autorização de maridos ou pais, seria pouco provável que elas pudessem se mudar para outra cidade. Assim, quando as fontes sinalizaram um "interesse" da população campo-grandense, poder-se-ia hipotetizar que tal interesse seria proveniente dessas mulheres que, agora, poderiam se inserir no Ensino Superior.

Nas lembranças de Pilatti (2017), ao falar sobre as alunas do curso de graduação em Psicologia:

Porque eles eram assim, não vou dizer que eram alunos só de classe alta, poder aquisitivo alto só! Tinha gente humilde também, gente de pouco poder aquisitivo fazendo o curso, se esforçando junto, e que, no entanto, se integrava perfeitamente com o pessoal, entendeu? Tinha assim de todas as classes e níveis sociais... Matutino e noturno! Então, quer dizer, por aí as pessoas já diziam: "Ah, esse é um curso só para ricos! Porque vai estudar de manhã e à noite, não vai precisar trabalhar!" Mas tinham muitos deles que trabalhavam à tarde. 
Todavia as aulas haviam sido organizadas para ocorrer em dois períodos - matutino e noturno -, o que dificultaria a possibilidade de empregos formais. O curso teria uma anuidade de $\mathrm{Cr} \$$ 4.500,00, a qual, inclusive, era veiculada como abaixo da média: "deve-se convir que a anuidade a ser cobrada será o valor mínimo, em relação à exigida pelos estabelecimentos de outros estados do país" (DIÁRIO DA SERRA, 1975a, p. 8). Vale lembrar, por exemplo, que o salário mínimo, à época, era de $\mathrm{Cr} \$ 532,80$, i.e., a anuidade do curso custaria pouco mais de oito salários. Assim, pelas fontes analisadas, o curso atenderia (i) a uma população ansiosa por cursos de graduação, (ii) composta, majoritariamente, por mulheres, rememoradas como maduras e politizadas, que precisavam de "autorização" para se matricular e (iii) disponibilidade para se organizar em mais de um turno de aulas. Desta forma, apesar de as memórias da entrevistada sinalizarem uma pluralidade de origens sociais do alunado do curso de graduação em Psicologia, podemos hipotetizar uma prevalência oriunda da classe média, dadas as condições anteriormente mencionadas. Todavia novos estudos precisariam ser analisados para compreender melhor a relação entre tais fatores.

\subsection{Currículo: docentes e discentes em ação}

Dessa forma, aquelas alunas, aparentemente maduras e politizadas, provenientes da classe média do estado, encontraram um curso de graduação em Psicologia associado à formação de professores. Seu engajamento nas disciplinas e, também, nas relações com os docentes foi rememorado pelos entrevistados como "comprometido". Inclusive, por vezes, isso poderia ocasionar algumas rusgas. Por exemplo, Teixeira (2016) explicou que o fato de ele ser um professor jovem e formado recentemente pareceu ter influenciado sua relação com os alunos, no sentido de causar algumas dificuldades. Ele diz: "Para os professores, principalmente para os novatos, igual a mim, né... já era um pouco mais complicado, lidar com todas as expectativas altas". Todavia o atendimento a tais "expectativas altas" ocasionava, segundo os entrevistados, uma relação de proximidade com os estudantes. Nessa direção, Macário (2016) diz: "[Tínhamos] uma relação de amizade, uma relação muito boa! Então acho que isso foi uma coisa importante para a psicologia na época". Em outra entrevista, vê-se:

A professora Magaly era muita extrovertida, ela é muito alegre, onde ela chegava fazia a festa! E assim como ela era na sala dos professores, ela era com os alunos em sala de aula. Então, muito amiga dos alunos, que nem o Luiz Salvador também! O Salvador final de semana reunia os alunos na casa dele para fazer churrasquinho, entendeu? Então ele tinha o respeito dentro sala de aula e a amizade dos alunos a ponto de eles irem para casa dele final de semana tomar banho de piscina, então era interessante essa continuidade do professor amigo, sabe? (PILATTI, 2017).

Do ponto de vista institucional, aquelas alunas encontraram, no curso de graduação em Psicologia da FADAFI/FUCMT, a operacionalização das exigências legais de forma idiossincrática (UNIVERSIDADE CATÓLICA DOM BOSCO [UCDB], s.d.). Em 1962, quando da regulamentação da profissão e formação em Psicologia no Brasil, além da promulgação da Lei n. 4.119, houve o estabelecimento de um currículo mínimo para "assegurar a Psicologia, a posição de relevo que lhe cabe no concerto das chamadas profissões liberais e, pari passu, evitar improvisões [sic] que, do charlatanismo a levariam, fatalmente ao descrédito" (BRASIL, 1962). Esse currículo pressupunha, para a formação no Bacharelado e na Licenciatura, as seguintes disciplinas: Fisiologia, Estatística, 
Psicologia Geral e Experimental, Psicologia do Desenvolvimento, Psicologia da Personalidade, Psicologia Social e Psicopatologia Geral. Para a obtenção do diploma de Psicólogo, terceira concentração prevista pela Lei n. 4.119, fazia-se necessária a oferta de Técnicas de Exame e Aconselhamento Psicológico e Ética Profissional. Além disso, a IES precisaria selecionar outras três disciplinas, do seguinte conjunto: Psicologia do Excepcional, Dinâmica de Grupos e Relações Humanas, Pedagogia Terapêutica, Psicologia Escolar e Problemas de Aprendizagem, Teorias e Técnicas Psicoterápicas, Seleção e Orientação Profissional e Psicologia Industrial.

No Regimento da FADAFI/FUCMT (UCDB, s.d.), no Capítulo II, foram listados os cursos de graduação. Entre eles, o curso de graduação em Psicologia, que, conforme sinalizado anteriormente, foi instalado como Licenciatura Plena (ver BRASIL, 1974). Mais adiante, no Capítulo III do referido Regimento, vê-se uma explicação sobre o funcionamento dos cursos de graduação da Faculdade, de forma que eles ocorressem em dois ciclos: o primeiro, básico, e o segundo, profissionalizante. Ainda no mesmo documento, observa-se que havia exigência de que as Licenciaturas também contassem com matérias pedagógicas, com o objetivo de preparar os alunos para a docência. Na estrutura geral, a Psicologia possuía uma organização própria, dentro daqueles ciclos, em que se lia, para o primeiro ciclo: (i) disciplinas obrigatórias - Língua Portuguesa, Sociologia, Psicologia Educacional, Antropologia, Introdução à Psicologia e Cultura Teológica e (ii) optativas - Matemática, Língua Inglesa, Língua Francesa, Física Geral e Experimental, Química Geral e qualquer outra matéria proposta pelo Conselho Departamental. Assim, nota-se que as matérias classificadas como obrigatórias, no primeiro ciclo, não constavam como obrigatórias no Currículo Mínimo do Conselho Federal de Educação (CFE) (BRASIL, 1962). Vale ressaltar que, em IES confessionais - como a FADAFI/FUCMT -, matérias como Cultura Teológica e Antropologia eram elencadas como obrigatórias. Com relação às outras matérias (Língua Portuguesa, Psicologia Educacional, Sociologia e Introdução à Psicologia), não se sabe ao certo quais as razões de classificá-las como obrigatórias, no curso de graduação em Psicologia da FADAFI/FUCMT. Talvez isso ocorresse por decisão do Conselho Departamental, com o objetivo de suprir as defasagens, conforme foi explicado na divisão entre os dois ciclos.

Ainda em referência ao Regimento da FADAFI/FUCMT (UCDB, s.d.), vê-se que o segundo ciclo do curso de graduação, em Psicologia, contava com dez disciplinas obrigatórias e quatro optativas. Respectivamente, nota-se (i) como obrigatórias - Fisiologia, Estatística, Psicologia Geral e Experimental, Psicologia do Desenvolvimento, Psicologia da Personalidade, Psicologia Social, Psicopatologia Geral, Técnicas de Exame e Aconselhamento Psicológico, Ética Profissional e Estágio Supervisionado; e (ii) como optativas - Relações Humanas, Teorias e Técnicas Psicoterápicas, Pedagogia Terapêutica e qualquer outra matéria proposta pelo Conselho Departamental. Essa organização indica que a IES considerava que várias das disciplinas dispostas, no currículo mínimo estabelecido pelo CFE, deveriam compor o ciclo de formação profissionalizante da Psicologia. Ou seja, ser profissional de Psicologia, no ideário daqueles que conformaram o curso, dependia de conhecimentos obrigatórios de Fisiologia e Estatística, entre outros. Chama a atenção o fato de o Estágio Supervisionado constar como disciplina obrigatória, já que o Regimento apresentava o curso de Psicologia como Licenciatura Plena. Embora as fontes pesquisadas não nos permitam fazer uma análise e, portanto, surge a necessidade de novas investigações, podemos hipotetizar que a presença de tal disciplina como obrigatória poderia sugerir intenções futuras no oferecimento da formação de Psicólogo, como previsto na Lei n. 4.119/62. 


\section{CONSIDERAÇÕES FINAIS}

A interpretação das fontes primárias, textuais e orais permite uma narrativa dos anos iniciais do curso de graduação em Psicologia da FADAFI/FUCMT, a qual se vincula ao fortalecimento de discursos e práticas de "modernização" do país. Esses discursos e práticas, embora presentes desde a instalação da República, no final do século XIX, intensificaram-se nos três primeiros quartis do século XX. Particularmente, entre os anos de 1930 e 1950, esse processo foi fortalecido a partir do ideário de ordenar para progredir, configurado como o mote da "modernização" nacional. A modernização, por sua vez, implicava na reestruturação dos diferentes níveis de ensino e, entre as décadas de 1960 e 1970, houve um enfoque no Ensino Superior. Nesse ínterim, o governo militar, instituído em 1964, operacionalizou uma reforma universitária articulada com diferentes atores sociais, entre eles, a Igreja. Assim, os resultados sugerem que a instalação de cursos de graduação, vinculados às "carreiras modernas" em voga, à época, permitiria atuar (i) na expansão para o Oeste, capitaneada pelo governo militar, e (ii) na intervenção das querelas entre o norte e o sul de Mato Grosso, cujas diferenças se acentuaram durante o segundo e terceiro quartil do século XX, sobretudo com a instalação da NOB.

Nesse cenário é que o caso específico do curso de graduação em Psicologia da FADAFI/ FUCMT se insere. Os resultados desta investigação sugerem que, se o estado necessitasse se articular com a iniciativa privada para a expansão e o fortalecimento do Ensino Superior em MT, a MSMT já teria infraestrutura e know-how na seara educacional. As obras educacionais dos salesianos, já presentes no Sudeste brasileiro, produziam impactos também na região CentroOeste. Além disso, tanto a Missão quanto a sociedade sulista de MT já demandavam expansões no Ensino Superior, particularmente em Campo Grande. Isso ocorria em decorrência dos processos de mudança ocasionados pelas práticas de comércio e pela gradativa urbanização do espaço citadino, consequências diretamente vinculadas à NOB. Os resultados indicam, ainda, que uma parcela particular da sociedade sulista do estado foi atendida: as mulheres. Elas foram descritas como maduras e politizadas, com "altas expectativas" em relação ao curso de graduação. As "altas expectativas" dessas alunas foram atendidas por um curso de graduação estruturado de forma idiossincrática, i.e., que manejou o currículo mínimo prescrito pelo CFE, de forma a atender as demandas do desenvolvimento local. Particularmente, demandas de licenciados para atuar no sistema educacional da região.

Por fim, considera-se relevante indicar algumas limitações metodológicas desta investigação. Parte das análises realizadas foi proveniente de entrevistas feitas com ex-professores do referido curso e, embora suas memórias possam auxiliar em uma compreensão de sua história, novas pesquisas poderiam recorrer a outros atores sociais. Citem-se, por exemplo, outros professores, de outras temporalidades, ou mesmo ex-alunos. Além disso, as reportagens analisadas não foram assinadas, portanto não é possível observar certas características do agenciamento das informações pautadas pela mídia local. Entretanto, apesar de limitações como essas, os resultados desta pesquisa lançam luz sobre a história do primeiro curso de graduação em Psicologia de Campo Grande e que, inclusive, foi o único até o final do século XX. Dessa maneira, eles contribuem para uma compreensão ampliada da história da Psicologia, no país, incorporando informações de regiões pouco exploradas, até o presente momento. Portanto eles auxiliam na identificação e preservação da memória da Psicologia no Brasil, no geral, e na região, em específico. 


\section{REFERÊNCIAS}

BITTAR, Mariluce; SILVA, Maria da Graça Martins da; VELOSO, Teresa Cristina Aguiar. Processo de interiorização da educação superior na Região Centro-Oeste: particularidades dos estados de Mato Grosso e Mato Grosso do Sul. Série-Estudos, Periódico do Programa de Pós-Graduação em Educação da UCDB, Campo Grande, MS, n. 16, p. 147-64, jul./dez. 2003.

BRASIL. Ministério da Educação. Conselho Federal de Educação. Parecer n. 3824/74. Aprovado em 7 de novembro de 1974. Assunto: Autorização para funcionamento do curso de Psicologia na Faculdade de Filosofia, Ciências e Letras. Brasília, 1974.

BRASIL. Ministério da Educação. Conselho Federal de Educação. Parecer n. 403/62. Aprovado em 19 de dezembro de 1962. Dispõe sobre o currículo mínimo e duração do curso de Psicologia. Diário Oficial da União, Brasília, 1962.

CARA, Bianca dos Santos et al. Universidade e psicologia no Diário da Serra: alguns apontamentos para uma história da Psicologia em Campo Grande. In: JACÓ-VILELA, Ana Maria; DEGANI-CARNEIRO, Filipe; ARAÚJO, João Henrique Queiroz de (Org.). Clio-Psyché - Saberes Psi: novos sujeitos, outras histórias. Curitiba: Juruá Editora, 2018. p. 83-93.

CASTRO, Afonso. História da Missão Salesiana de Mato Grosso (1894-2008). Campo Grande, MS: UCDB, 2014.

CORSI, Pietro. A política da teoria na história da ciência. In: ARDIGÓ, Fabiano (Org.). História de uma ciência regional: cientistas e suas instituições no Paraná (1940-1960). São Paulo: Contexto, 2011. p. 7-16.

DIÁRIO DA SERRA. Aulas de Psicologia Clínica iniciarão em agosto, na FUCMT. Campo Grande, 1975a.

DIÁRIO DA SERRA. Mulheres invadem a FUCMT. Campo Grande, 1975b.

DIÁRIO DA SERRA. Vestibular de Psicologia: outra conquista das mulheres. Campo Grande, 1975c.

FERRAZ, Denise Pereira de Alcântara. Memórias e histórias do curso de Psicologia da Faculdade de Lorena: uma contribuição para a historiografia da Psicologia no Brasil. 2014. 200 p. Tese (Doutorado em Psicologia Social)- Centro de Educação e Humanidades - Instituto de Psicologia, Universidade do Estado do Rio de Janeiro, Rio de Janeiro, 2014.

MACÁRIO, Irma. Entrevista concedida a Graciela F. Silva Delmondes. Campo Grande, 25 de março de 2016.

MARGOTTO, Lilian Rose; SOUZA, Maria Cecília Cortez Christiano de. A constituição de um curso de psicologia durante a ditadura civil-militar no Brasil: investigação a partir dos relatos dos primeiros professores. Memorandum, Belo Horizonte/Ribeirão Preto, n. 32, p. 58-77, abr. 2017.

MOTTA, Rodrigo Pato de Sá. As universidades e o regime militar: cultura política brasileira e modernização autoritária. Rio de Janeiro: Zahar, 2014.

PILATTI, Aurenice Rodrigues Pinheiro. Entrevista concedida a Graciela F. Silva Delmondes. Campo Grande, 2 de março de 2017.

PIÑEDA, María Andrea; JACÓ-VILELA, Ana Maria. Ciencia psicológica y profesionalización en Argentina y Brasil: 1930-1980. Universitas Psychologica, Bogotá, v. 13, n. 5, p. 2015-33, 2014.

PORTUGAL, Francisco Teixeira; FACCHINETTI, Cristiana; CASTRO, Alexandre de Carvalho. História social da Psicologia. Rio de Janeiro: NAU, 2018. 
REIS, Maria Teodorowic. Entrevista concedida a Graciela F. Silva Delmondes. Campo Grande, 20 de agosto de 2016.

RODRIGUES, Divino de Jesus da Silva. A história da Psicologia no Brasil: 40 anos do curso de Psicologia da PUC Goiás. Goiânia: Ed. da PUC Goiás, 2013.

ROMERO, Arnaldo. O lugar dos bacharéis: história da criação da Faculdade de Direito, Fadir de Campo Grande, MT (1965-1970). 2005. 164 p. Dissertação (Mestrado em Educação) - Universidade Federal de Mato Grosso do Sul, Campo Grande, MS, 2005.

SÁ JUNIOR, Luiz Salvador de Miranda. Entrevista concedida a Graciela F. Silva Delmondes. Campo Grande, 23 de julho de 2016.

SALVATIERRA, Belén. Hace 30 años se hizo realidad: creación de la Facultad de Psicología y Relaciones Industriales de la UNSA. Revista de Psicología de Arequipa, Arequipa, Peru, v. 5, n. 1, p. 102-12, jan./jun. 2015.

SAMPAIO, Helena. O ensino superior no Brasil: o setor privado. São Paulo: FAPESP/ Hucitec, 2000.

SIDONE, Otávio José Guerci; HADDAD, Eduardo Amaral; MENA-CHALCO, Jesús Pascual. A ciência nas regiões brasileiras: evolução da produção e das redes de colaboração científica. Transinformação, Campinas, SP, v. 28, n. 1, p. 15-31, jan./abr. 2016.

TEIXEIRA, Benedito Juberto. Entrevista concedida a Graciela F. Silva Delmondes. Campo Grande, 2 de agosto de 2016.

UCDB. Livro de Regimento da FADAFI. Campo Grande, MS, s.d..

\section{Sobre os autores:}

Graciela Ferreira Delmondes: Mestre, bacharel e licenciada em Psicologia pela Universidade Católica Dom Bosco (UCDB). Formação em Psicanálise pela Sociedade Psicanalítica de Mato Grosso do Sul (SPMS/ 2009) - instituição pertencente à International Psychoanalytical Association (IPA). Docente no curso de Psicologia da UNIDERP. Atua em consultório particular como psicoterapeuta e psicanalista. E-mail: gracieladelmondes@yahoo.com.br, Orcid: http://orcid.org/0000-0002-1449-0261

Rodrigo Lopes Miranda: Doutor e mestre em Educação pela Universidade Federal de Minas Gerais (UFMG). Professor do Programa de Pós-Graduação em Psicologia da Universidade Católica Dom Bosco (UCDB). Coordenador do Grupo de Trabalho em História da Psicologia e Presidente da Sociedade Brasileira de História da Psicologia (SBHP). E-mail: rlmiranda@ucdb.br, Orcid: http://orcid.org/0000-0003-3222-7368 